\title{
TOLERÂNCIA DE SEMENTES DE LINHAGENS DE MILHO À ALTA TEMPERATURA DE SECAGEM
}

\author{
Tolerance of corn lines seeds to high drying temperature \\ Solange Carvalho Barrios Roveri José ${ }^{1}$, Édila Vilela de Resende Von Pinho ${ }^{2}$, \\ Renzo Garcia Von Pinho' ${ }^{2}$ César Martoreli da Silveira ${ }^{3}$
}

\begin{abstract}
RESUMO
Cultivares tolerantes a altas temperaturas de secagem proporcionam redução no tempo de secagem, uma etapa crítica no sistema de produção de sementes de milho (Zea mays L.). Nesta pesquisa, foi avaliada a tolerância à alta temperatura de secagem de sementes de linhagens de milho, por meio de testes de germinação e vigor. As sementes foram colhidas manualmente em espigas com teor de água em torno de $35 \%$ e secas artificialmente à $45^{\circ} \mathrm{C}$ até atingirem $11 \%$ de teor de água. Em seguida, foram submetidas aos testes de primeira contagem e contagem final de germinação, envelhecimento acelerado, teste de frio sem solo e de condutividade elétrica. Houve diferenças significativas nos valores de germinação e vigor de sementes das diferentes linhagens, sendo então classificadas em tolerantes e intolerantes. Pelos resultados, conclui-se que a sensibilidade das sementes à injúria por secagem à alta temperatura é dependente da linhagem.
\end{abstract}

Termos para indexação: Sementes, Zea mays, qualidade fisiológica, secagem.

\begin{abstract}
High drying temperature tolerant cultivars provide a reduction in the drying period, a critical phase of the corn seeds (Zea mays L.) production system. In this research the tolerance of corn lines seeds to high drying temperature was evaluated by the germination and vigor tests. Seeds were handpicked in ears with water content around $35 \%$ and dried artificially at $45^{\circ} \mathrm{C}$ up to $11 \%$ water content. Then, the seeds were submitted to the first and final germination counting tests, accelerated aging, cold test without soil and electrical conductivity. There were significant differences in the germination and vigor values of seeds from different lines, being classified into tolerant and intolerant. The results permitted to conclude that sensitivity of seeds to high drying temperature injury depends on the lines.
\end{abstract}

Index terms: Seeds, Zea mays, physiology quality, drying.

(Recebido para publicação em 30 de junho de 2003 e aprovado em 27 de setembro de 2004)

\section{INTRODUÇÃO}

A produção de sementes é uma atividade especializada, e cuidados devem ser despendidos em todas as fases de produção para assegurar ao máximo a obtenção de lotes de sementes com alta qualidade. O momento mais adequado para a colheita das sementes é o mais próximo possível da maturidade fisiológica. No caso do milho, a maturidade das sementes pode ocorrer num conteúdo de água em torno de 28 a $42 \%$, dependendo do genótipo em questão (CARTER e PONELEIT, 1973). Objetivando a produção de sementes com qualidade superior e a viabilização das estruturas de secagem e beneficiamento, tem sido dada preferência à colheita em espigas.
O aumento da eficiência na colheita requer uma secagem mais rápida, com a adoção de temperaturas de secagem e vazões de ar mais elevadas. Entretanto, temperaturas altas reduzem a germinação e o vigor das sementes, podendo alterar suas características químicas e físicas, e a suscetibilidade da semente aos danos por secagem é função das condições de secagem, do conteúdo de água e da qualidade iniciais da semente, aliada aos aspectos genéticos (CHEN e BURRIS, 1991). Navratil (1981) observou que a susceptibilidade das sementes à injúria por secagem varia com o tipo de genótipo, havendo diferenças entre as linhagens quando essas são utilizadas como parental feminino ou masculino.

A causa primária do dano por altas temperaturas de secagem tem sido a desestruturação do sistema de membranas celulares. Assim como nos danos causados

\footnotetext{
1. Engenheira Agrônoma, Dra. em Produção e Tecnologia de Sementes, Departamento de Agricultura/Setor Sementes - Universidade Federal de Lavras/UFLA, Caixa Postal 3037 - 37200-000 - Lavras, MG.

2. Professores, Doutores - Departamento de Agricultura/UFLA

3. Acadêmico do curso de Agronomia; bolsista de iniciação científica da FAPEMIG/UFLA
} 
por secagem, as membranas são tidas como o local onde ocorrem os danos por embebição à baixa temperatura, reduzindo a germinação e o crescimento de plântulas (HERTER e BURRIS, 1989a). Burris e Navratil (1980), trabalhando com sementes de milho, concluíram que a injúria por secagem pode aumentar a susceptibilidade à injúria ao frio, porém, a resistência de uma não pode ser relacionada com a resistência da outra.

$\mathrm{O}$ efeito da temperatura de dessecação sobre a funcionabilidade da mitocôndria também tem sido pesquisado. A mitocôndria, uma organela do citoplasma, é fonte primária de energia durante a germinação e subseqüente crescimento da plântula (MADDEN e BURRIS, 1995). Burris et al. (1997) observaram que temperatura elevada de secagem resultou em cristas mitocondriais pouco visíveis.

Numa revisão conduzida por Baker et al. (1991), a maioria das sementes de milho com teor de água acima de $25 \%$ é seca numa temperatura de $35^{\circ} \mathrm{C}$, e abaixo desse teor, a $40-43^{\circ} \mathrm{C}$. Segundo Amaral e Dalpasquale (2000), para a secagem de milho em espigas, a temperatura do ar de secagem varia entre 40 e $50^{\circ} \mathrm{C}$, não devendo ultrapassar esse limite para não comprometer a qualidade fisiológicas das sementes.

Cultivares tolerantes a altas temperaturas de secagem podem proporcionar redução no tempo de secagem, uma etapa crítica no sistema de produção de sementes de milho. Estudos da variabilidade genética para a tolerância a danos por secagem são bastante escassos e praticamente inexistentes sob condições brasileiras. Assim, propôs-se com este trabalho estudar as diferenças existentes entre genótipos de milho (Zea mays L.), por meio de aspectos fisiológicos que reflitam essa tolerância à alta temperatura de secagem.

\section{MATERIAL E MÉTODOS}

Inicialmente foi instalado um campo para multiplicação de 31 linhagens provenientes do programa de melhoramento de milho da UFLA. A semeadura, realizada em novembro, foi conduzida de modo a garantir seis plantas por metro linear, e o espaçamento utilizado foi de $0,8 \mathrm{~m}$. As adubações, bem como os tratos culturais, foram realizados conforme as recomendações para a cultura. $\mathrm{Na}$ época de florescimento, as espigas foram protegidas com sacos plásticos antes da emissão dos estilo-estígmas, para evitar cruzamentos indesejáveis e, posteriormente, foram realizadas as autofecundações. Durante o desenvolvimento das sementes, foi feito um acompanhamento da solidificação do endosperma por meio da linha de leite e as espigas foram amostradas pa- ra determinação do teor de água, utilizando-se do método da estufa a $130^{\circ} \mathrm{C}$, por 4 horas, conforme prescrições das Regras para Análise de Sementes (BRASIL, 1992), até que o teor de água atingisse aproximadamente 35\%, momento esse em que foi realizada a colheita.

As espigas, correspondentes a cada linhagem, foram colhidas e despalhadas manualmente e, em seguida, submetidas à secagem artificial a $45^{\circ} \mathrm{C}$, até as sementes atingirem o conteúdo de água de aproximadamente $11 \%$. Para a secagem das espigas, foram utilizados secadores experimentais de pequena escala, construídos de acordo com Navratil e Burris (1982), e o fluxo médio de ar foi de $23,0 \mathrm{~m}^{3} \mathrm{~min}^{-1} \mathrm{t}^{-1}$.

As espigas foram debulhadas manualmente e as sementes retidas na peneira 16 de crivo circular foram tratadas com os fungicidas Tecto $600^{\circledR}$ ( Thiabendazole) (24 g do i.a./100 kg de sementes) e Captan $750 \mathrm{TS}$ (Captan) (90 g do i.a./100 kg de sementes). A avaliação da qualidade fisiológica das sementes foi realizada pelos testes de: germinação - conduzido com quatro repetições de 50 sementes, que foram semeadas entre papeltoalha tipo Germitest umedecido com água destilada na proporção de 2,5 mL:1g de papel. As sementes permaneceram no germinador regulado para $25^{\circ} \mathrm{C}$, e as avaliações das plântulas normais foram efetuadas segundo as recomendações das Regras para Análise de Sementes (BRASIL, 1992). Os resultados foram expressos em porcentagem; primeira contagem de germinação - as plântulas normais que apresentavam pelo menos duas raízes seminais, raiz principal e parte aérea com $1,5 \mathrm{~cm}$ de comprimento foram computadas aos quatro dias da semeadura do teste de germinação, e os resultados, expressos em porcentagem; teste de frio sem solo - cinqüienta sementes por repetição foram distribuídas em papel-toalha umedecido com água destilada numa proporção de três vezes o seu peso seco, perfazendo um total de duzentas sementes por tratamento. Os rolos foram confeccionados como no teste de germinação e, após semeadura, foram colocados no interior de sacos plásticos e mantidos em câmara regulada a $10^{\circ} \mathrm{C}$ durante 7 dias. Decorrido esse prazo, os rolos foram transferidos para o germinador regulado para $25^{\circ} \mathrm{C}$, e as plântulas normais avaliadas aos 7 dias (DIAS e BARROS, 1995); teste de condutividade elétrica quatro repetições de 25 sementes aparentemente intactas foram selecionadas e pesadas $(0,01 \mathrm{~g})$ para cada tratamento. Em seguida, foram imersas em $75 \mathrm{~mL}$ de água destilada por 24 horas à temperatura de $25^{\circ} \mathrm{C}$. Por meio de um condutivímetro de massa, marca DIGIMED, modelo CD 21A, foi efetuada a leitura da condutividade da solução de embebição das sementes de cada linhagem e

Ciênc. agrotec., Lavras, v. 28, n. 5, p. 1107-1114, set.out., 2004 
os resultados expressos em $\mu \mathrm{S} / \mathrm{cm} / \mathrm{g}$ de sementes (MARCOS FILHO et al., 1987) e envelhecimento acelerado - o método utilizado foi o de minicâmaras do tipo "gerbox", onde as sementes foram distribuídas sobre uma tela suspensa no interior da caixa contendo $40 \mathrm{~mL}$ de água. As sementes permaneceram incubadas durante 96 horas numa temperatura de $41^{\circ} \mathrm{C}$ e, em seguida, foi efetuado o teste de germinação. A avaliação das plântulas normais foi realizada aos 9 dias (VIEIRA e CARVALHO, 1994).

Sementes colhidas em espigas com o mesmo conteúdo de água e secas à sombra foram submetidas ao teste de germinação.

Os testes realizados para avaliação da qualidade fisiológica das sementes seguiram o delineamento experimental inteiramente casualizado com quatro repetições. Os dados foram interpretados estatisticamente por meio da análise de variância, e as médias comparadas pelo teste de Scott Knott ao nível de 5\%. As análises foram realizadas no programa estatístico Sis Var (Sistema de Análise de Variância) (FERREIRA, 2000) e as variáveis, expressas em porcentagem, tiveram os dados transformados em arco-seno $\sqrt{\% / 100}$.

\section{RESULTADOS E DISCUSSÃO}

O resumo da análise de variância dos dados obtidos nos testes para avaliação da qualidade fisio- lógica das sementes de linhagens de milho, submetidas à alta temperatura de secagem, está registrado na Tabela 1. Houve diferenças significativas nos valores de germinação e vigor das sementes das linhagens de milho submetidas à secagem artificial a $45^{\circ} \mathrm{C}$.

Embora Amaral e Dalpasquale (2000) tenham citado temperaturas de até $50^{\circ} \mathrm{C}$ na secagem de milho em espigas, a temperatura de $45^{\circ} \mathrm{C}$ utilizada neste experimento parece ter sido satisfatória para discriminar os materiais.

Maiores valores de germinação foram observados para as sementes das linhagens 42, 86, 91, 65 e 40 e menores para as das linhagens 57, 41, 74, 43 e 84 . Nessas últimas, houve uma redução drástica na porcentagem de plântulas normais (Tabela 2).

Com esses resultados, reforçam-se as afirmações feitas por Baker et al. (1991), os quais mencionaram que a redução da germinação não é devida ao efeito acumulativo da exposição das sementes às condições de alto teor de água e elevada temperatura de secagem, mas sim devida aos danos causados às membranas celulares ou desorganização dos componentes celulares, os quais são dependentes do genótipo. Nesta pesquisa, todas as sementes foram submetidas às mesmas condições de produção e secagem, demonstrando que as diferenças observadas na tolerância à alta temperatura de secagem foi dependente da linhagem em questão.

TABELA 1 - Resumo da análise de variância dos dados obtidos do teste de germinação (TG); primeira contagem do teste de germinação $\left(1^{\mathrm{a}} \mathrm{C}\right)$; envelhecimento acelerado $(\mathrm{EA})$; teste de frio $(\mathrm{TF})$ e condutividade elétrica $(\mathrm{CE})$ de sementes de linhagens de milho secas artificialmente.

\begin{tabular}{lcccccc}
\hline \multirow{2}{*}{ F.V } & G.L & \multicolumn{5}{c}{ Quadrados Médios } \\
\cline { 3 - 7 } & & $\mathbf{T G}^{\mathbf{1}}$ & $\mathbf{1}^{\mathbf{a}} \mathbf{C}^{\mathbf{1}}$ & $\mathbf{E A}^{\mathbf{1}}$ & $\mathbf{T F}^{\mathbf{1}}$ & $\mathbf{C E}$ \\
Linhagens & 30 & $0,2556^{* *}$ & $0,2633^{* *}$ & $0,5371^{* *}$ & $0,3167^{* *}$ & $249,7707^{* *}$ \\
Erro & 93 & 0,0042 & 0,0051 & 0,0073 & 0,0063 & 3,8819 \\
\hline \multirow{2}{*}{ Média geral } & & 1,11 & 0,78 & 0,79 & 0,95 & 7,93 \\
\hline
\end{tabular}

${ }^{1}$ Dados transformados em arco - seno $\sqrt{\% / 100}$

**Teste $\mathbf{F}$ significativo a $1 \%$ de probabilidade 
TABELA 2 - Valores médios da primeira contagem $\left(1^{\mathrm{a}} \mathrm{C}\right)$ e contagem final do teste de germinação (TG), teste frio (TF), envelhecimento acelerado (EA) e condutividade elétrica (CE) de sementes de linhagens de milho secas artificialmente.

\begin{tabular}{|c|c|c|c|c|c|c|c|c|c|c|c|c|c|c|}
\hline \multirow{2}{*}{$\begin{array}{l}L \\
42\end{array}$} & \multicolumn{2}{|c|}{ TG (\%) } & \multirow{2}{*}{$\begin{array}{c}\text { L } \\
91\end{array}$} & \multicolumn{2}{|c|}{$\mathbf{1}^{\mathrm{a}} \mathrm{C}(\%)$} & \multirow{2}{*}{$\begin{array}{c}\mathbf{L} \\
91\end{array}$} & \multicolumn{2}{|c|}{$\mathrm{TF}(\%)$} & \multirow{2}{*}{$\begin{array}{c}\text { L } \\
91\end{array}$} & \multicolumn{2}{|c|}{ EA (\%) } & \multirow{2}{*}{$\begin{array}{c} \\
83\end{array}$} & \multicolumn{2}{|c|}{$\mathrm{CE}(\mu \mathrm{S} / \mathrm{cm} / \mathrm{g})$} \\
\hline & 100 & $\mathrm{a}$ & & 92 & $\mathrm{a}$ & & 99 & A & & 99 & $\mathrm{a}$ & & 14.52 & $\mathrm{a}$ \\
\hline 86 & 99 & $\mathrm{a}$ & 40 & 91 & $\mathrm{a}$ & 86 & 98 & A & 65 & 98 & $\mathrm{a}$ & 33 & 15.18 & $\mathrm{a}$ \\
\hline 91 & 99 & $\mathrm{a}$ & 76 & 84 & $b$ & 40 & 97 & A & 40 & 95 & $\mathrm{~b}$ & 65 & 15.69 & $\mathrm{a}$ \\
\hline 65 & 99 & $\mathrm{a}$ & 30 & 79 & $\mathrm{~b}$ & 65 & 97 & A & 86 & 95 & $\mathrm{~b}$ & 48 & 16.89 & b \\
\hline 40 & 99 & $\mathrm{a}$ & 65 & 76 & $\mathrm{~b}$ & 42 & 91 & B & 30 & 91 & $\mathrm{c}$ & 91 & 17.20 & b \\
\hline 30 & 95 & $\mathrm{~b}$ & 6 & 76 & $\mathrm{~b}$ & 76 & 87 & $\mathrm{~b}$ & 42 & 86 & $\mathrm{c}$ & 40 & 18.16 & $\mathrm{~b}$ \\
\hline 76 & 93 & $\mathrm{~b}$ & 86 & 65 & $\mathrm{c}$ & 33 & 86 & $\mathrm{~b}$ & 76 & 77 & $\mathrm{~d}$ & 42 & 19.03 & $\mathrm{~b}$ \\
\hline 63 & 90 & $\mathrm{~b}$ & 54 & 65 & $\mathrm{c}$ & 30 & 84 & $\mathrm{~b}$ & 19 & 64 & $\mathrm{e}$ & 19 & 19.06 & $\mathrm{~b}$ \\
\hline 33 & 89 & $\mathrm{~b}$ & 93 & 62 & $\mathrm{c}$ & 6 & 83 & $\mathrm{~b}$ & 25 & 64 & $\mathrm{e}$ & 86 & 20.19 & $\mathrm{c}$ \\
\hline 6 & 86 & $\mathrm{c}$ & 19 & 59 & $\mathrm{c}$ & 79 & 73 & $\mathrm{c}$ & 48 & 52 & $\mathrm{f}$ & 57 & 20.64 & $\mathrm{c}$ \\
\hline 93 & 86 & $\mathrm{c}$ & 31 & 57 & $\mathrm{c}$ & 19 & 70 & $\mathrm{c}$ & 33 & 51 & $\mathrm{f}$ & 6 & 20.92 & c \\
\hline 54 & 86 & $\mathrm{c}$ & 48 & 54 & $\mathrm{~d}$ & 93 & 70 & $\mathrm{c}$ & 81 & 50 & $\mathrm{f}$ & 93 & 21.22 & c \\
\hline 81 & 84 & $\mathrm{c}$ & 25 & 50 & $\mathrm{~d}$ & 54 & 70 & $\mathrm{c}$ & 83 & 50 & $\mathrm{f}$ & 64 & 21.38 & $\mathrm{c}$ \\
\hline 29 & 82 & $\mathrm{~d}$ & 64 & 49 & $\mathrm{~d}$ & 29 & 67 & $\mathrm{c}$ & 6 & 49 & $\mathrm{f}$ & 81 & 21.39 & c \\
\hline 25 & 80 & $\mathrm{~d}$ & 33 & 48 & $\mathrm{~d}$ & 81 & 64 & $\mathrm{c}$ & 36 & 47 & $\mathrm{f}$ & 25 & 23.05 & d \\
\hline 83 & 79 & $\mathrm{~d}$ & 74 & 47 & $\mathrm{~d}$ & 95 & 64 & $\mathrm{c}$ & 66 & 45 & $\mathrm{f}$ & 79 & 23.84 & d \\
\hline 19 & 78 & $\mathrm{~d}$ & 79 & 44 & $\mathrm{~d}$ & 25 & 63 & $\mathrm{c}$ & 93 & 45 & $\mathrm{f}$ & 78 & 24.06 & d \\
\hline 48 & 76 & e & 63 & 44 & $\mathrm{~d}$ & 48 & 61 & $\mathrm{c}$ & 95 & 44 & $\mathrm{f}$ & 95 & 24.03 & d \\
\hline 78 & 73 & $\mathrm{e}$ & 42 & 43 & $\mathrm{~d}$ & 83 & 57 & $\mathrm{~d}$ & 31 & 43 & $\mathrm{f}$ & 29 & 24.78 & d \\
\hline 36 & 72 & $\mathrm{e}$ & 83 & 41 & $\mathrm{~d}$ & 64 & 54 & $\mathrm{~d}$ & 54 & 42 & $\mathrm{f}$ & 50 & 25.55 & d \\
\hline 66 & 71 & $\mathrm{e}$ & 36 & 40 & $\mathrm{e}$ & 63 & 54 & $\mathrm{~d}$ & 63 & 41 & $\mathrm{f}$ & 63 & 25.62 & d \\
\hline 95 & 71 & $\mathrm{e}$ & 78 & 37 & $\mathrm{e}$ & 57 & 53 & $\mathrm{~d}$ & 79 & 37 & $\mathrm{~g}$ & 54 & 26.55 & d \\
\hline 79 & 71 & $\mathrm{e}$ & 95 & 36 & $\mathrm{e}$ & 31 & 52 & $\mathrm{~d}$ & 64 & 36 & $\mathrm{~g}$ & 31 & 28.08 & $\mathrm{e}$ \\
\hline 64 & 67 & $\mathrm{f}$ & 43 & 36 & $\mathrm{e}$ & 66 & 51 & $\mathrm{~d}$ & 74 & 33 & $\mathrm{~g}$ & 43 & 29.45 & $\mathrm{e}$ \\
\hline 50 & 66 & $\mathrm{f}$ & 81 & 34 & $\mathrm{e}$ & 36 & 48 & $\mathrm{~d}$ & 29 & 30 & $\mathrm{~g}$ & 76 & 30.68 & e \\
\hline 31 & 64 & $\mathrm{f}$ & 29 & 33 & $\mathrm{e}$ & 78 & 45 & $\mathrm{~d}$ & 57 & 26 & $\mathrm{~h}$ & 30 & 31.08 & e \\
\hline 57 & 56 & $\mathrm{~g}$ & 50 & 32 & $\mathrm{e}$ & 50 & 43 & $\mathrm{~d}$ & 50 & 22 & $\mathrm{~h}$ & 74 & 33.62 & $f$ \\
\hline 41 & 57 & $\mathrm{~g}$ & 57 & 27 & $\mathrm{e}$ & 43 & 37 & $\mathrm{e}$ & 41 & 19 & $\mathrm{~h}$ & 36 & 33.91 & f \\
\hline 74 & 56 & $\mathrm{~g}$ & 66 & 26 & $\mathrm{e}$ & 41 & 34 & $\mathrm{e}$ & 78 & 13 & $\mathrm{i}$ & 41 & 34.86 & $f$ \\
\hline 43 & 55 & $\mathrm{~g}$ & 41 & 15 & $\mathrm{f}$ & 74 & 25 & $\mathrm{f}$ & 43 & 1 & $\mathrm{j}$ & 66 & 37.46 & g \\
\hline 84 & 11 & $\mathrm{~h}$ & 84 & 1 & $\mathrm{~g}$ & 84 & 9 & $\mathrm{~g}$ & 84 & 0 & $\mathrm{j}$ & 84 & 51.80 & $\mathrm{~h}$ \\
\hline
\end{tabular}

Médias seguidas pela mesma letra na coluna não diferem entre si pelo teste Scott-Knott a $5 \%$.

Ciênc. agrotec., Lavras, v. 28, n. 5, p. 1107-1114, set.out., 2004 
$\mathrm{Na}$ Tabela 3 estão apresentados os valores de germinação das sementes colhidas em espigas com $35 \%$ de conteúdo de água e secas à sombra. Devido à falta de sementes de algumas linhagens durante a produção de sementes, não foi possível apresentar os dados de germinação de todas as linhagens. A germinação das sementes foi afetada pelo processo de secagem, uma vez que as sementes de algumas linhagens, colhidas com o mesmo teor de água e secas à sombra, apresentaram valores de germinação acima de $90 \%$ (Tabela 3), pressupondo, assim, que as sementes no momento da colheita estavam fisiologicamente maduras e com elevada qualidade fisiológica. Exemplificando, as sementes das linhagens 84,43 e 74, que foram intolerantes à alta temperatura de secagem (Tabela 2), quando colhidas com elevado teor de água e secas à sombra (Tabela 3), apresentaram uma germinação mais elevada. Sendo assim, as diferenças de qualidade fisiológica das sementes das linhagens observadas após secagem à alta temperatura não se mantiveram na secagem conduzida à sombra.

No teste de envelhecimento acelerado (Tabela 2), menores valores foram observados nas sementes das linhagens $57,50,41,78,43$ e 84, não ocorrendo o mesmo com as sementes das linhagens $91,65,40,86,30$, e 42, que mantiveram sua capacidade de produzir plântulas normais mesmo após secagem a alta temperatura. Além da perda de integridade do sistema de membranas celulares, provocando alterações degenerativas no metabolismo da semente, o teste de envelhecimento acelerado pode ter provocado a morte de tecidos importantes, em diferentes regiões das sementes, como mencionado por Matthews (1985), citado por Marcos Filho (1994), podendo explicar a alta porcentagem de sementes mortas de algumas linhagens após envelhecimento acelerado (Tabela 4). Braccini et al. (2001) mencionaram que, além dos danos às membranas celulares, deve-se considerar o acúmulo de substâncias tóxicas, principalmente os açúcares redutores, como um dos principais mecanismos de deterioração em sementes de milho, pelo fato de serem os carboidratos as principais substâncias de reserva.

Com relação aos resultados do teste frio, houve uma mesma tendência de classificação das linhagens quanto à tolerância à alta temperatura de secagem observada no teste de envelhecimento acelerado e germinação (Tabela 2). Maior dano por alta temperatura de secagem foi observado nas sementes submetidas ao teste frio, quando comparado ao teste de germinação. Esses resultados foram observados também por Herter e Burris (1989a) e Navratil e Burris (1984). O baixo teor de água das sementes associada com "chilling" durante embebição pode resultar num maior dano à estrutura da membrana e subseqüente germinação (CAL e OBENDORF, 1972). A temperatura de secagem pode ter alterado o mecanismo básico da configuração das membranas, resultando em severas reduções na germinação das linhagens intolerantes no teste frio. $\mathrm{O}$ efeito da temperatura de secagem foi também detectado no teste frio em pesquisa desenvolvida por Madden e Burris (1995). Os autores observaram que sementes de milho híbrido tiveram sua viabilidade reduzida após secagem conduzida à temperatura de $45^{\circ} \mathrm{C}$.

TABELA 3 - Valores médios do teste de germinação (TG) de linhagens de milho colhidas com 35\% de umidade e secas à sombra.

\begin{tabular}{cc}
\hline Linhagens & Germinação $(\%)$ \\
\hline 42 & 96 \\
40 & 98 \\
86 & 99 \\
65 & 99 \\
91 & 100 \\
50 & 92 \\
57 & 98 \\
43 & 97 \\
41 & 99 \\
74 & 100 \\
84 & 97 \\
54 & 100 \\
83 & 91 \\
19 & 92 \\
81 & 100 \\
25 & 91 \\
48 & 99 \\
\hline
\end{tabular}

$\mathrm{O}$ teste de primeira contagem de germinação avalia a velocidade de germinação, ou seja, o vigor inicial das sementes. Com exceção das linhagens 42 e 74 , as demais mantiveram-se tolerantes ou susceptíveis aos danos por secagem, como detectado nos demais testes para a avaliação da qualidade fisiológica das sementes.

Antes de prejudicar a porcentagem ou o desenvolvimento das plântulas normais, a secagem excessiva reduz a velocidade de germinação e, em casos mais severos, eleva a freqüência de anormalidades nas plântulas (ROBERTS, 1981). Essas diferenças de comporta- 
mento entre as linhagens quanto à velocidade de germinação pode ser atribuída à presença de um sistema funcional enzimático mitocondrial nas sementes secas, que para Nakayama et al. (1990), citados por Burris e Madden (1993), é importante para a absorção inicial de oxigênio pelos tecidos hidratados.

Não houve uma relação direta entre perda de lixiviados, avaliada pelo teste de condutividade elétrica, e o grau de sensibilidade à alta temperatura de secagem para as linhagens 30 e 57, as quais apresentaram-se como tolerantes e susceptíveis, respectivamente, quando comparadas com os resultados observados nos demais testes utilizados para a avaliação da qualidade fisiológica das sementes. Torna-se difícil estabelecer limites de valores de condutividade que estariam refletindo na qualidade fisiológica das sementes, medida por meio de outros testes. Rosa (2000) observou valores de $25,23 \mu \mathrm{S} / \mathrm{cm} / \mathrm{g}$ em sementes de linhagem de milho colhidas com teores de água de $37,2 \%$ e secas artificialmente a $50^{\circ} \mathrm{C}$. Essas sementes apresentaram valores de primeira contagem e contagem final de $57 \%$ e $87 \%$, respectivamente, e $30 \%$ no teste frio. No entanto, na presente pesquisa, o aumento de lixiviados observados nas sementes da linhagem 30 não foi suficiente para reduzir a porcentagem de plântulas normais nos testes de vigor e germinação.

As membranas celulares são citadas como um dos principais locais de injúrias após dessecação, sendo um indicador precoce de dano induzido por secagem, pela lixiviação de várias soluções citoplasmáticas, como mencionado por Crowe et al. (1987). Pode ocorrer que determinados genótipos apresentem uma maior eficiência na reorganização do sistema de membranas, não significando propriamente em danos. De acordo com Herter e Burris (1989b), a injúria às membranas pela secagem, avaliada pelo teste de condutividade elétrica, teve maior importância ou não, dependendo da linhagem, como observado neste trabalho, e que outros tipos de danos podem afetar a viabilidade, sem aumentar os valores de condutividade elétrica.

De acordo com Leprince et al. (1995), a perda de eletrólitos em sementes de milho e feijão tolerantes não foi afetada pela temperatura durante o processo de secagem. Fessel et al. (2001) observaram que os valores de condutividade elétrica das sementes de linhagem de milho colhidas com teores de água entre 52 e $21,5 \%$ decresceram com o desenvolvimento da semente, indicando a existência de diferenças na per- meabilidade das membranas celulares durante o processo de maturação.

TABELA 4 - Valores médios de sementes mortas do teste de envelhecimento acelerado de linhagens de milho secas artificialmente.

\begin{tabular}{|c|c|}
\hline Linhagens & Sementes mortas $(\%)$ \\
\hline 42 & 13 \\
\hline 40 & 1 \\
\hline 86 & 2 \\
\hline 65 & 2 \\
\hline 91 & 0 \\
\hline 30 & 8 \\
\hline 76 & 13 \\
\hline 63 & 56 \\
\hline 33 & 48 \\
\hline 6 & 21 \\
\hline 93 & 43 \\
\hline 54 & 53 \\
\hline 81 & 36 \\
\hline 29 & 20 \\
\hline 25 & 34 \\
\hline 83 & 36 \\
\hline 19 & 29 \\
\hline 48 & 39 \\
\hline 78 & 67 \\
\hline 36 & 32 \\
\hline 66 & 45 \\
\hline 95 & 29 \\
\hline 79 & 29 \\
\hline 64 & 62 \\
\hline 50 & 74 \\
\hline 31 & 40 \\
\hline 57 & 57 \\
\hline 41 & 76 \\
\hline 74 & 49 \\
\hline 43 & 81 \\
\hline 84 & 76 \\
\hline
\end{tabular}


Não somente a temperatura do ar de secagem afeta a qualidade fisiológica das sementes, como também a taxa de secagem, que segundo Baker et al. (1991), varia com o híbrido utilizado. Burris e Navaratil (1980) também comprovaram que sementes de linhagem de milho tolerantes apresentaram uma maior taxa de secagem, seguida da linhagem intermediária e intolerante.

Nesta pesquisa foi possível verificar grandes variações de vigor e germinação das sementes das linhagens que foram submetidas às mesmas condições de secagem. Esses resultados reforçam a idéia de que a sensibilidade das sementes ao processo de secagem, bem como ao processo de deterioração, varia com o genótipo.

\section{CONCLUSÕES}

Sementes de linhagens de milho apresentam diferenças significativas nos valores de germinação e de vigor após secagem artificial, indicando que a susceptibilidade à injúria por alta temperatura de secagem é dependente da linhagem.

\section{REFERÊNCIAS BIBLIOGRÁFICAS}

AMARAL, D.; DALPASQUALE, V. A. Custos de secagem de sementes de milho (Zea mays L.) em espigas usando simulação matemática. Engenharia Agrícola, Jaboticabal, v. 20, n. 1, p. 55-66, 2000.

BAKER, K. D.; PAULSEN, M. R.; ZWEDEN, J. van. Hibrid and drying rate effects on seed corn viability. Transactions of the ASAE, Saint Joseph, v. 34, n. 2, p. 499-506, 1991.

BRACCINI, A. de L. E.; BRACCINI, M. do C. L.; SCAPIM, C. A. Mecanismos de deterioração das sementes: aspectos bioquímicos e fisiológicos. Informativo ABRATES, Londrina, v. 1, n. 1, p. 10-15, 2001

BRASIL. Ministério da Agricultura e Reforma Agrária. Regras para análise de sementes. Brasília, 1992. $365 \mathrm{p}$.

BURRIS, J. S.; MADDEN, R. F. Early germination physiology in maize embryos damaged by high temperature desiccation. Seed Science, Angers, v. 2, p. 491-496, 1993.

BURRIS, J. S.; NAVRATIL, R. J. Drying highmoisture seed corn. Proceedings Annual Corn Sorghum Research Congress, Dordrecht, v. 35, p. 116-132, 1980.
BURRIS, J. S.; PETERSON, J. M.; PERDOMO. Morphological and physiological changes associated with desiccation in maize embryos. In: INTERNATIONAL WORKSHOP ON SEEDS: BASIC AND APPLIED ASPECTS OF SEED BIOLOGY, 5., 1995, Reading. Proceedings... Reading: University of Reading, 1997. p. 103-111.

CAL, J. P.; OBENDORF, R. L. Imbibitional chilling injury in Zea Mays L. altered by initial kernel moisture and maternal parent. Crop Science, Madison, v. 12, n. 3, p. 369-373, 1972

CARTER, M. W.; PONELEIT, C. G. Black layer maturity and fillingperiod among inbreed lines of corn (Zea mays L.). Crop Science, Madison, v. 13, n. 4, p. 436-476, 1973

CHEN, Y.; BURRIS, J. S. Desiccation tolerance in maturing maize seed: membrane phospholipid composition and thermal properties. Crop Science, Madison, v. 30, n. 3, p. 766-770, May/June 1991.

CROWE, J. H.; CROWE, L. M.; CARPENTER, J. F.; AURELL WISTROM, C. Stabilization of dry phospholipid bilayers and proteins by sugars. Biochemical Journal, London, v. 242, n. 1, p. 1-10, 1987.

DIAS, M. C. L. de; BARROS, A. S. do R. Avaliação da qualidade de sementes de milho. Londrina: IAPAR, 1995. 41 p. (Circular, 88).

FERREIRA, D. F. Análises estatísticas por meio do Sisvar para Windows versão 4.0. In: REUNIÃO ANUAL DA REGIÃO BRASILEIRA DA SOCIEDADE INTERNACIONAL DE BIOMETRIA, 45., 2000, São Carlos, SP. Anais... São Carlos: UFSCar, 2000. p. 255-258.

FESSEL, S. A.; VIEIRA, R. D.; MENDONÇA, E. A. F. de; CARVALHO, R. V. de. Maturidade fisiológica de sementes de milho. Revista Brasileira de Sementes, Londrina, v. 23, n. 1, p. 191-197, 2001.

HERTER, U.; BURRIS, J. S. Changes in moisture, temperature, and quality of corn seed during hightemperature drying. Canadian Journal Plant Science, Otttawa, v. 69, n. 3, p. 749-761, 1989a.

HERTER, U.; BURRIS, J. S. Evaluating drying injury on corn seed with a conductivity test. Seed 
Science and Technology, Zürich, v. 17, n. 1, p. 625638, 1989 b.

LEPRINCE, O.; VERTUCCI, C. W.; HENDRY, G. A. F.; ATHERTON, N. M. The expression of desiccation induced damage in orthodox seeds is a function of oxygen and temperature. Physiologia Plantarum, Copenhagen, v. 94, n. 2, p. 233-240, 1995.

MADDEN, R. F.; BURRIS, J. S. Respiration and mitochondrial characteristics of imbibing maize embryos damaged by high temperatures during desiccation. Crop Science, Madison, v. 35, n. 6, p. 1661-1667, 1995.

MARCOS FILHO, J. Teste de envelhecimento acelerado. In: VIEIRA, R. D.; CARVALHO, N. M. de. Testes de vigor em sementes. Jaboticabal: FUNEP, 1994. p. 133-149.

MARCOS FILHO, J.; CÍCERO, S. M.; SILVA, S. M.; SILVA, W. R. da. Avaliação da qualidade das sementes. Piracicaba: ESALQ, 1987. 230 p.

NAVRATIL, R. J. The effect of drying temperature on corn seed quality. 1981. Thesis (PhD) - Iowa State University, Ames, 1981.
NAVRATIL, R. J.; BURRIS, J. S. Small-scale dryer designer. Agronomy Journal, Madison, v. 74, n. 1, p. 159-161, 1982.

NAVRATIL, R. J.; BURRIS, J. S. The effect of drying temperature on corn seed quality. Canadian Journal of Plant Science, Ottawa, v. 64, n. 3, p. 487496, 1984.

ROBERTS, E. H. Physiology of ageing and its application to drying and storage. Seed Science Technology, Zurich, v. 9, n. 2, p. 359-372, 1981.

ROSA, S. D. V. F. da. Indução de tolerância à alta temperatura de secagem em sementes de milho por meio de pré-condicionamento a baixa temperatura. 2000. 121 p. Tese (Doutorado em Fitotecnia) - Universidade Federal de Lavras, Lavras, 2000.

VIEIRA, R. D.; CARVALHO, N. M. de. Testes de vigor em sementes. Jaboticabal: FUNEP, 1994. $166 \mathrm{p}$. 